\title{
The Prevalence Study of Ovine Fasciolosis in Jima Rare District, Horo Guduru Wollega Zone, Oromia Regional State, Western Ethiopia
}

\author{
Kebede Shanko* and Wakgari Olgira
}

Haramaya University, Collage of Veterinary Medicine, P.O.Box 138, Dire Dawa, Ethiopia

*Corresponding author: Kebede Shanko, Haramaya University, Collage of Veterinary Medicine, P.O.Box 138, Dire Dawa, Ethiopia, Tel: +251-25-5530391; E-mail: Sh.kebeko@yahoo.com

Rec date: Aug 13, 2015; Acc date: Nov 30, 2015; Pub date: Dec 2, 2015

Copyright: @ 2015 Shanko K, et al. This is an open-access article distributed under the terms of the Creative Commons Attribution License, which permits unrestricted use, distribution, and reproduction in any medium, provided the original author and source are credited.

\begin{abstract}
A cross-sectional study on the prevalence of ovine fasciolosis was conducted in Jima Rare District from January 2013 to June 2014. A total of 384 faecal samples were randomly collected directly from the rectum of individual animals. Parasitological investigation was performed using sedimentation technique. From a total of 384 coprologically examined sheep 214 animals were found positive for fasciolosis with an overall prevalence of $55.7 \%$. Gemeda, Shumbo, kalo Guracha, Burka Hobo and Bekela Erer Peasant Associations (PAs) accounted for 47.36\%, $50.6 \%, 64.47 \%, 58.97 \%$ and $57.14 \%$ respectively. The difference in the prevalence in the five PAs was not statistically significant $(p>0.05)$. The prevalence of ovine fasciolosis was computed for the different age, sex and body condition categories. The prevalence rate of fasciolosis in young sheep $50.8 \%$ was less than in adults sheep $59.8 \%$ and the difference were not statistically significant $(P>0.05)$. The prevalence of fasciolosis in two sex groups in the present study was $55.89 \%, 55.5 \%$ in female and male respectively. The difference in the prevalence was not significantly significant $(p>0.05)$. On the other hand in present study area the prevalence of fasciolosis was found to be higher in sheep with poor body condition than those with medium and good body condition ones with an overall prevalence of $67.8 \%, 51.8 \%$ and $43.68 \%$ respectively. There is no statically deference $(p>0.05)$ between three types of BCS. It was concluded that ovine fasciolosis was prevalent, thus causing major economic loss in the study area. Hence, control strategies targeted on the parasite and the intermediate hosts as well as implementation of appropriate grazing management in the study area are warranted.
\end{abstract}

Keywords: Ovine fasciolosis; Jima rare; Prevalence

\section{Introduction}

Ethiopia hosts large number of small ruminants that are raised under external pastoral production system or in adjunct to crop production. The estimated small ruminant population of Ethiopia is about 25, 017, 218 sheep's and 21, 884, 222 goats. However this huge potential of wealth is untapped to the livelihood of village farmers and the contribution to national economy at large is minimal. The reason being predominance of infectious and parasitic disease, age-old traditional management system, lack of genetic selection for good performance coupled with under and malnutrition and absence of well-developed market infrastructure. Both infectious and parasitic diseases are common traits that affect productivity. Parasitic disease possesses a serious health trait and limits the productivity of livestock due to the associated morbidity and mortality.

There is many in numbers of parasitic disease are incriminated to play a detrimental role in hampering small ruminant production. GIT helmenthosis is considered as one of the major parasitic problem that constrained livestock improvement programs in Ethiopia. One of the helmenthosis that cause direct or indirect losses especially in domestic ruminants is fasciolosis. Fasciola species is the most important Trematode of domestic ruminants. Fascioliasis is the commonest of liver fluke disease in the temperate of the world. The complete life cycle of Fasciola is realized by the presence of suitable intermediate host under favorable condition. Snail is the essential intermediate host for the development of Miracidium through Metacercariae which is an infective stage for the final host. There are three main factors influencing the production of the large numbers of Metacercariae necessary for outbreaks of Fasciolosis. Those factors are availability of snail habitat (i.e., Lymnaea truncatula prefers mud to free water), temperature $\left(10^{\circ} \mathrm{C}\right.$ and above) and moisture for the breeding of snail and for the development of fasciola [1].

Fasciolosis can be caused by the F. hepatica, which is widely distributed in temperate and cooler areas of high altitude in tropics and subtropics areas and F. gigantica which is widely distributed in tropical areas.

Fasciolosis, caused by F.hepatica and F.gigantica, is one of the most prevalent helminthes infections of ruminants in different parts of the world. It causes significant morbidity and mortality $[2,3]$.

Since Fasciolosis is major parasitic disease of small ruminants, an estimate of economic loss due to ovine fasciolosis in the Ethiopia highlands was made based on available data on mortality, weight loss, reduced reproduction efficiency, and liver condemnation at slaughter. The economic effects of fasciolosis where identified and models for estimating the financial loss presented. Ovine fasciolosis losses were estimated at 48.4 mills. Birr per/yr of which $46.5,48.8$ and $4.7 \%$ were due to mortality, productivity or weight loss and reproductive wastage and liver condemnation respectively. These losses can be reduced substantially by fasciolosis control programs that may be including the use of antihelmentics, grazing management and nutritional supplementation [4].

Considerable work has been done on the prevalence of ovine Fasciolosis in many parts of the Ethiopia. However no report so far has been published on the level of ovine fasciolosis in the present study 
area, where small ruminants are important assets to the local farmers Hence, this research was conducted to meet the following objectives:

To determine the prevalence of Ovine fasciolosis in the Jimma Rare District, Horo Guduru Wollega, Ethiopia.

To identify major risk factors of the disease.

\section{Materials and Methods}

\section{Study area}

These theses has been conducted in Oromo region, Horo Guduru Wollega zone, Jimma Rare District (Woreda), which is locted $245 \mathrm{~km}$ far from capital city of Ethiopia (Addis Abeba) to the west direction. Jimma Rare woreda is the district located to the east part of the zone. It is formed as woreda administration during 1984. Today this woreda is sub divided to into 18 peasant associations (PAs) for its administrative propose. Wayu is capital city town of the woreda located $96 \mathrm{~km}$ away from zonal city Shambu. The Jimma Rare woreda is laying on $34,375.375$ hector of land. From this about 3305.047 hector of land is used for grazing, 20,625hector is used for crop production, 5800 hector land is covered by muddy (marsh land), 329.14 hector is used for construction and about 329.14 hector land is used for social purpose.

The study area is located at an altitude between 1650-2650 m with an average $2150 \mathrm{~m}$ above sea level. The temperature of the area varies between 18-25, with average 21.5 and the annual average rainfall is around $1150 \mathrm{~mm}$. The area has subtropical (weyndega), tropical (kola) and temperate (dega) type of climate division and accounting for $72 \%$, $0 \%$ and $28 \%$ respectively. The livestock population of the woreda is estimated at 56,708 cattle, 26,183 sheep's, 9,612 goats, 4,276 horse, 960 mule, 2,623 donkey, 28,037 poultray and 19,396 bee colonies. The number of the dogs and cats are unknown in the district.

\section{Study animals and sampling method}

The study has been done on Indigenous sheep those known by name "Horo breed", they have tin tail type and most of the time known by giving twin birth. In the district where this study has been done, they kept under traditional extensive management system. The populations of the sheep's live in the District (woreda) are estimated to 26,037 in number. The study has been done on 384 sheep's selected from the five (5) peasant associations, namely Gameda, Shumbo, Burka hobo, Kalo guracha and Bekela Erer. The study site and individual animals have been selected by simple random sampling method. The fecal sample collected directly from the rectum of the $o$ animals was preserved by formalin before transported to laboratory.

\section{Study Design}

A cross sectional study was conducted from January 2014-June 2014 to determine the prevalence of ovine fasciolosis in Jimma Rare District, Oromia Regional State, Western Ethiopia.

\section{Sample size determination}

To determine the sample size, the expected prevalence of ovine Fascioliasis in Jima Rare District would be taken into consideration by 50\%. According to Thrusfield M [5] the formula for the sample size determination with $95 \%$ confidence interval and at 5\% absolute precision is calculated as follows:

$$
\mathrm{n}=\frac{1.96^{2} \mathrm{P}_{\exp ^{(1-\mathrm{P}} \exp ^{)}}}{\mathrm{d}^{2}} \text { Where: }
$$

$\mathrm{n}=$ required sample size

Pexp=expected prevalence

$\mathrm{d} 2=$ Desired absolute precision confidence level $=95 \%$

$$
\begin{aligned}
& \mathrm{n}=\frac{1.962 \times 0.5(1-0.5)}{(0.05)^{2}}=384 \text { sheepSample collection and coproslogicl } \\
& \text { examination }
\end{aligned}
$$

Feacal Sample collected randomly for the study from the selected five peasant association (PAs). Namely, Gameda, Shumbo, Kalo guracha, Burka Hobo, and Bekela erer PAs. A total 384 samples are collected and all the samples are taken directly from the rectum of the sheep by using glove and sampling bottle. Samples collected from PAs such as Kalo guracha, Shumbo and Burka hobo those having distance from laboratory are preserved by formalin before they transported for examination. During sampling age, sex and BCs of each animal has been recorded.

Examination of the fasciolosis egg has been done by using different laboratory equipments and tools such as Beaker, Strainer, Measuring Cylinder, Mortar and Pestle, Test Tube, Test Tube Rack, Microscope Slide, Cover Slip, Microscope, Centrifuge and Refrigerator. According to the investigation procedure for the examination of Fasciola egg was as follows: About 3 gram of feces was collected from the rectum of each selected sheep using sample bottle. The fecal sample was crushed with mortar and pestle and 40-50 $\mathrm{ml}$ of tap water was added and mixed with fork and filtered the fecal suspension through a tea strainer into a beaker, the filtered material should be poured into a centrifuge tube. After balance the centrifuge tubes, centrifuged the sample at about $1500 \mathrm{rpm}$ for three minutes the supernatant fluid was discarded carefully using a pipette and bulb, transferred a small amount of the top of the layer of the sediment to a microscope slide and covered with cover slip, Then examined under 40 x's magnification power.

\section{Determination of age}

Since most small ruminant holder farmers do not usually keep records; it was difficult to obtain information on the age of animals from the owner. Hence age of every sampled sheep was determined based on dentition as indicated by [6] and conveniently categorized as young and adults.

\section{Body condition score}

Body condition score of each animal was determined based on criteria set by [7] using the 5 point scale ( $1=$ very thin to $5=$ obes).it can be assessed by palpation around the lumbar vertebrae between the back of the ribs and the front of the pelvic bones. However; for in this study, the animals were categorized in poor, medium and good body condition.

\section{Data analysis}

Data collected from laboratory result was stored on Microsoft (Ms) excel spread sheet program, and analysis was done by using SPSS Version 20 software program. The total prevalence was calculated by dividing the number of fasciola positive animals by the total number of animals tested or sampled. Pearson's chi-square $\left(\chi^{2}\right)$ was used to evaluate the association of different variables with the prevalence of 
Page 3 of 4

fasciolosis. P-value less than 0.05 (at $5 \%$ level of significance in all analysis).

\section{Result}

From a total of 384 examined sheep fecal samples, 214 samples were positive for fasciolosis eggs with an overall prevalence $55.7 \%$. The prevalence of Ovine fasciolosis recorded in the five Peasant Associations (PAs) were $47.36 \%, 50.6 \%, 64.47 \%, 58.97 \%$ and $57.14 \%$ in Gameda, Sumbo, Kalo guracha, Burka hobo, and Bekela Erer respectively. This difference in prevalence was not statically significance $(\mathrm{p}>0.05)$ (Table 1$)$.

\begin{tabular}{|l|l|l|l|}
\hline Pas & No of examined & No of positive & Prevalence (\%) \\
\hline Gameda & 76 & 36 & 47.36 \\
\hline Shumbo & 77 & 39 & 50.64 \\
\hline Kalo guracha & 76 & 49 & 64.47 \\
\hline Burka Hobo & 78 & 46 & 58.97 \\
\hline Bekela erer & 77 & 44 & 57.14 \\
\hline Total & 384 & 214 & 55.72 \\
\hline
\end{tabular}

Table 1: The prevalence of ovine Fasciolosis in different Pas. $\chi^{2}=4.695$, $\mathrm{p}=0.320$.

The prevalence of fasciolosis in female and male sheep was $55.89 \%$ $(109 / 195)$ and $55.7 \%(105 / 189)$ respectively. However the difference were not statically significance between the sexes $(\mathrm{p}>0.05)$ (Table 2$)$.

\begin{tabular}{|l|l|l|l|}
\hline Sex & No of examined & No of positive & Prevalence (\%) \\
\hline Female & 195 & 109 & 55.89 \\
\hline Male & 189 & 105 & 55.5 \\
\hline Total & 384 & 214 & 55.7 \\
\hline
\end{tabular}

Table 2: The prevalence of ovine Fasciolosis in different sex. $\chi^{2}=0.494$, $\mathrm{p}=0.494$.

The infestation rate between young $(<2 \mathrm{yr})$ and adult $(\geq 2)$ sheep were compared. It was observed that the prevalence of fasciolosis was relatively higher in adult than younger with $59.8 \%$ nd $50.8 \%$ which is statically not significant $(\mathrm{p}>0.05)$ (Table 3$)$.

\begin{tabular}{|l|l|l|l|}
\hline Age groups & No of examined & No of positive & Prevalence (\%) \\
\hline young's(<2yr) & 181 & 89 & 50.8 \\
\hline Adults( $\geq 2 \mathrm{yr})$ & 203 & 125 & 59.8 \\
\hline Total & 384 & 214 & 55.72 \\
\hline
\end{tabular}

Table 3: prevalence of ovine fasciolosis on the age bases. $\chi^{2}=2.154$, $\mathrm{p}=0.142$.

On the other hand in present study area the prevalence of fasciolosis was found to be higher in sheep with poor body condition than those with medium and good body condition ones with an overall prevalence of $67.8 \%(99 / 146), 51.8 \%(70 / 235)$ and $43.68 \%(45 / 103)$ respectively. There is not statically deference $(p>0.05)$ between three types of BCS (Table 4).

\begin{tabular}{|l|l|l|l|}
\hline Body condition score & No of examined & No of positive & Prevalence (\%) \\
\hline Poor & 146 & 99 & 67.8 \\
\hline Medium & 135 & 70 & 51.8 \\
\hline Good & 103 & 45 & 43.68 \\
\hline Total & 384 & 214 & 55.7 \\
\hline
\end{tabular}

Table 4: The prevalence of ovine Fasciolosis on the bases of body condition score. $\chi^{2}=3.348 \mathrm{p}=0.187$.

\section{Discussion}

Fasciolosis is a prevailing ruminant health predicament and causes substantial economic losses to the livestock commerce in Ethiopia. The prevalence indicated by fecal examination in the present study was $55.7 \%$.This finding has some similarity with the study by Beyazen [8] 53\% reported in Eastern Gojam. But it was lower as compared to the study conducted by $[9,10]$ having a prevalence of $73 \%, 70.2 \%$ respectively. The reason of the deference in the prevalence may be related to the diversity of agro-climate conditions, management system of the animal or altitude of the study area. Accordingly the prevalence of the ovine fasciolosis in present study area in deferent Peasant Associations (PAs) were $47.36 \%$ (36/76), 50.6\% (39/77), $64.47 \%$ (49/76), 58.97(46/78)\% and 57.14 \% (44/77) in Gameda, Sumbo, Kalo guracha ,Burka hobo, and Bekela erer respectively were has been observed. This variation in result from one another may be from the presence of wide part of land covered by muds or swampy lands especially in PAs to PAs with high rate of prevalence. In another way the swampy areas were important ecologies for the continuity of the lifecycle of fasciolosis. Similar findings were previously reported $[1,11,12]$. So, it is the reason for the prevalence of fasciolosis at high rate in some PAs of the study area.

Young animals had a lower prevalence of Fasciola spp infections in this study. This finding was consistent with other reports, and it was not surprising because naive kids have maternal immunity. Higher infection rates were found in adults in other age groups. Based on this finding, it can be suggested that the higher exposure risk of adults may be due to physiological differences, such as stress, pregnancy, lambing, inadequate nutrition, and infectious diseases. Similar results were reported by Chanie M [10].

Solomon W has suggested that fascioliasis equally affect both sexes. In this study, a higher prevalence of parasitic infection was not associated with sex $(\mathrm{P}>0.05)$ [12]. The fact that prevalence of fasciolosis between male and female are not significantly difference is may indicate that sex of sheep has not impact on the prevalence of fasciolosis. They exposed to graze and parasitic infection with equal rate. This result is Similar to the observation done by [13] which is $49.9 \%$.

In this study the result indicated that higher infection rate of fasciolosis was recorded in sheep with poor body condition than medium and good body condition animals. So it indicates that fasciolosis parasitic disease cause highly reducing of body weight. 
Citation: Shanko k, Olgira W (2016) The Prevalence Study of Ovine Fasciolosis in Jima Rare District, Horo Guduru Wollega Zone, Oromia Regional State, Western Ethiopia. J Veterinar Sci Technol 7: 277. doi:10.4172/2157-7579.1000277

Page 4 of 4

\section{Conclusion and Recommendations}

In conclusion, this study has investigated the prevalence of ovine fasciolosis in Horo breed sheep reared under extensive farming system in Jimma Rare District of the Oromia Regional state, western Ethiopia. The prevalence of the disease based on faecal sedimentation test in this district was considerably accounted about $55.7 \%$. It was relatively higher in those with poor body condition score than with good BCS. This indicated that ovine fasciolosis disease causes loss of body weight that put the owners or farmers into bankruptcy. These present study suggest that further strategic control of snails is required in order to overcome the problems of ovine fasciolosis at the study area.

Therefore based on the above findings the following recommendations are forwarded:

A further study using alternative techniques such as serology in combination with fecal test surveys need to be conducted in different seasons in order to generate more complete data on the prevalence of ovine fasciolosis.

Appropriate strategic deworming has to be designed and implemented in the study area to minimize the effect of the disease on livestock productivity.

Strategic vectors Control through different techniques should be undertaken so that minimize the risk of fasciolosis in the area in order to improve or boosting the livestock productivity of an area.

Collaboration between different sectors should be done so as to control both disease and vectors of an area.

Policy makers and economy analysts have to be provoked to put their relentless effort in the control of such disease that has serious impact on the country economy.

\section{References}

1. Urquhart M, Armour JL, Dunchan AM, Jennings FW (1996) Veterinary Parastiology (2Edn). Scotland well science Ltd pp: 102-112.
2. Okewole EA, Ogundipe GA, Adejinmi JO, Olaniyan AO (2000) Clinical Evaluation of three Chemo prophylactic Regimes against Ovine Helminthosis in a Fasciola Endemin Farm in Ibadan, Nigeria. Israel Journal of Veterinary Medicine 56: 15-28.

3. WHO (2000) Control of food bore trematode infectious technical report series 849: 617.

4. Anderson N, Luong TT, Bui KL, Smoker PM (1999) The sensitivity and sepesifisty of two method for detection Fasiola in catele. Journal of veternery parasitology 83: 15-24.

5. Thrusfield M (2005) Veterinary epidemiology (3rdedn). Black well Science UK, pp: 178-197.

6. Ganteby RM (1991) Sheep the Tropical Agriculturalist. Macmillan education Limited, London and Basingstoke pp: 1-2.

7. Thompson J, Meyer H (1994) Body condition scoring of sheep. Troncy PM (Ed) Fascioliasis of ruminants. In: Manual of tropical veterinary parasitology.

8. Beyazen C (1995) Preliminary study on epidemiology of fasciolosis in Eastern Gojam region. DVM Thesis, Faculty of Veterinary Medicine, Addis Ababa, University, DebreZeit, Ethiopia.

9. Yadeta B (1994) Epidemiology of bovine and ovine fascioliasis and distribution of its snail intermediate host in western Shoa. DVM Thesis, Addis Ababa University, DebereZeit, Ethiopia p: 35.

10. Chanie M, Begashaw S (2012) Assessment of the Economic Impact and Prevalence of Ovine Fasciolosis in Menz Lalo Midir District, Northeast Ethiopia. Vet World 5: 261-264.

11. Graber M (1975) Helminths and helminthiasis of domestic and wild animals in Ethiopia. Bull Animal Health Prod Afr pp: 57.

12. Solomon W (1965) Effect of strategic anthelmintic treatment intervention on ruminant fasciolosis in Upper Blue Nile Basin, North Western Ethiopia. Addis Ababa: Addis Ababa University p. 78.

13. Ayalew T (1994) Preliminary survey of sheep helminthiasis in Kimbibit district, North Shoa 8th Conference of the Ethiopian Veterinary Association, Addis Ababa, Ethiopia. Ethiopian Veterinary Association pp: 86-94. 